\title{
Polyphenols for improvement of inflammation and symptoms in rheumatic diseases: systematic review
}

\author{
Hillary Nascimento Coletro', Amanda Popolino Diniz", Nathália Sernizon Guimarães"', Júlia Cristina Cardoso Carraro"v, \\ Raquel de Deus Mendonça ${ }^{\mathrm{v}}$, Adriana Lúcia Meireles ${ }^{\mathrm{v}}$
}

Universidade Federal de Ouro Preto (UFOP), Ouro Preto (MG), Brazil

\begin{abstract}
'MSc. Doctoral Student, Postgraduate Program on Health and Nutrition, School of Nutrition, Universidade Federal de Ouro Preto (UFOP), Ouro Preto (MG), Brazil; Doctoral Student, Grupo de Pesquisa e Ensino em Nutrição e Saúde Coletiva (GPENSC), Ouro Preto (MG), Brazil.

(D) https://orcid.org/0000-0002-9142-6079

"MSc. Doctoral Student, Postgraduate Program on Health and Nutrition, School of Nutrition, Universidade Federal de Ouro Preto (UFOP), Ouro Preto (MG), Brazil; Doctoral Student, Grupo de Pesquisa e Ensino em Nutrição e Saúde Coletiva (GPENSC), Ouro Preto (MG), Brazil.

(D) https://orcid.org/0000-0002-3300-0440

I'PhD. Former Postdoctoral Fellow in the Postgraduate Program on Health and Nutrition, School of Nutrition, Universidade Federal de Ouro Preto (UFOP), Ouro Preto (MG), Brazil.

(D) https://orcid.org/0000-0002-0487-0500
\end{abstract}

wPhD. Adjunct Professor, Department of Clinical and Social Nutrition, Universidade Federal de Ouro Preto (UFOP), Ouro Preto (MG), Brazil; Adjunct Professor, Grupo de Pesquisa e Ensino em Nutrição e Saúde Coletiva (GPENSC), Ouro Preto (MG), Brazil.

(D) https://orcid.org/0000-0003-0027-2690

vphD. Adjunct Professor, Department of Clinical and Social Nutrition, School of Nutrition, Universidade Federal de Ouro Preto (UFOP), Ouro Preto (MG), Brazil; Adjunct Professor, Grupo de Pesquisa e Ensino em Nutrição e Saúde Coletiva (GPENSC), Ouro Preto (MG), Brazil.

(D) https://orcid.org/0000-0001-7599-8715

vphD. Adjunct Professor, Department of Clinical and Social Nutrition, School of Nutrition, Universidade Federal de Ouro Preto (UFOP), Ouro Preto (MG), Brazil; Adjunct Professor, Grupo de Pesquisa e Ensino em Nutrição e Saúde Coletiva (GPENSC), Ouro Preto (MG), Brazil.

(D) https://orcid.org/0000-0002-1447-953X

KEYWORDS (MeSH terms):

Antioxidants.

Rheumatic diseases.

Polyphenols.

Rheumatoid arthritis.

Osteoarthritis.

AUTHORS' KEYWORDS:

Phenolic compounds.

Nutrition.

Epidemiology.

Human health.

\begin{abstract}
BACKGROUND: Rheumatic diseases (RDs) are a group of pathological conditions characterized by inflammation and functional disability. There is evidence suggesting that regular consumption of polyphenols has therapeutic effects capable of relieving RD symptoms.

OBJECTIVE: To synthesize data from randomized controlled trials on administration of polyphenols and their effects on RD activity.

DESIGN AND SETTING: Systematic review conducted at Universidade Federal de Ouro Preto, Minas Gerais, Brazil.

METHODS: A systematic search was conducted in the databases PubMed (Medline), LILACS (BVS), IBECS (BVS), CUMED (BVS), BINACIS (BVS), EMBASE, Web of Science and Cochrane Library and in the grey literature. The present study followed a PRISMA-P checklist.

RESULTS: In total, 646 articles were considered potentially eligible, of which 33 were then subjected to complete reading. Out of these, 17 randomized controlled trials articles were selected to form the final sample. Among these 17 articles, $64.71 \%$ assessed osteoarthritis $(n=11), 23.53 \%$ rheumatoid arthritis $(n=4), 5.88 \%$ rheumatoid arthritis and fibromyalgia $(n=1)$ and $5.88 \%$ osteoarthritis and rheumatoid $(n=1)$. Intake of polyphenol showed positive effects in most of the studies assessed (94.12\%): it improved pain (64.70\%) and inflammation (58.82\%).

CONCLUSION: Polyphenols are potential allies for treating RD activity. However, the range of polyphenol sources administered was a limitation of this review, as also was the lack of information about the methodological characteristics of the studies evaluated. Thus, further primary studies are needed in order to evaluate the effects of polyphenol consumption for reducing RD activity.

SYSTEMATIC REVIEW REGISTER: PROSPERO - CRD42020145349.
\end{abstract}

\section{INTRODUCTION}

Rheumatic diseases (RDs) belong to a group of chronic musculoskeletal pathological conditions characterized by joint damage, inflammation, pain, functional disability and impact on individuals' quality of life. ${ }^{1-4}$ Rheumatic diseases include chronic clinical conditions of multicausal etiopathogenesis characterized by disruption of immunological tolerance, production of autoantibodies, production of a number of substances accounting for lesions in many body structures, ${ }^{4}$ mechanical stress in the joints and changes to the alignment of bones, cartilage and other structures necessary for joint stability. ${ }^{5}$

They give rise to a heterogeneous group of clinical conditions, such as rheumatoid arthritis, osteoarthritis, scleroderma, systemic sclerosis, ankylosing spondylitis, fibromyalgia, osteoporosis, tendinitis, gout and lupus, among others. Osteoarthritis (OA) and rheumatoid arthritis (RA) are the most common RDs. ${ }^{3} \mathrm{OA}$ is the first chronic, inflammatory and degenerative disease that arises through joint cartilage wear or loss. ${ }^{2} \mathrm{RA}$ is an inflammatory disease that mainly affects joints without being degenerative. Instead, it causes structural damage and joint inflammation, which result in progressive structural and functional losses. ${ }^{4}$

RDs are more common in developed countries and in women. In Europe and North America, their prevalence is $0.5 \%-1.0 \%{ }^{6} \mathrm{OA}$ is the most common form of arthritis, affecting approximately 14 million people in the United States. ${ }^{7}$ Moreover, RA affects about five in every 1,000 adults and the number of individuals affected is expected to rise to approximately 67 million by $2030 .{ }^{8}$

Many treatments for diminishing RD activity are available. These include tumor necrosis factor-alpha inhibitors and the disease-modifying anti-rheumatic drugs (DMARDs) infliximab, 
etanercept, certolizumab pegol, golimumab, adalimumab, tocilizumab, abatacept, rituximab, tofacitinib, baricitinib, upadacitinib, secukinumab, ustekinumab, ixekizumab, guselkumab and belimumab. However, these can be costly and can have side effects like abdominal pain, back pain, chest pain and nausea. ${ }^{8}$

Diet therapy can be used to assist RD therapies, since it helps to reduce pain and inflammation effects. ${ }^{9}$ The Nurses' Health Study cohort showed lower RA incidence among individuals who followed healthy dietary patterns (as assessed using the Healthy Eating Index, HEI-2010) than among individuals who followed inadequate dietary patterns. ${ }^{10}$ Regular consumption of fresh fruits, vegetables and spices rich in phytochemicals can mitigate oxidative stress and inflammation, and relieve symptoms. ${ }^{11}$

The therapeutic effects of phytochemicals, especially polyphenols, on RDs have been studied, given their antioxidant, anti-inflammatory and immunomodulatory properties. ${ }^{3}$ Polyphenols are metabolites found in plants that are produced in metabolic pathways triggered by plant interactions with environmental factors. They are involved in plant reproduction and in communication between plants, as well as in their defense against pathogens. Polyphenols are found in vegetables, fruits, cocoa and nuts, and also in their derivatives, such as juices and teas. ${ }^{12}$

Epidemiological studies have presented associations between polyphenol intake and RDs, ${ }^{13-15}$ and experimental studies on animal models and in vitro investigations about the role played by polyphenols in RDs have been conducted. Diets rich in bioactive compounds are associated with improvement of disease activity, since these substances act as protective factors against inflammatory processes and against endothelial dysfunction linked to development of worsening of clinical signs and symptoms. ${ }^{3}$

A systematic review of the literature showed that total flavonoids and specific subclasses of flavonoids such as flavanols, flavanones, flavones, isoflavones and anthocyanins (but without addressing total polyphenols in diets) are associated with low risk of developing diabetes, cardiovascular events and mortality. ${ }^{16}$ However, to the best of our knowledge, no systematic review has been conducted with the aim of evaluating the association between administration of polyphenols and RD symptoms.

\section{OBJECTIVE}

The aim of the present article was to review the effects of polyphenols on RD activity, based on information available in the literature (randomized clinical trials).

\section{METHODS}

\section{Protocol and registration}

The present systematic review was conducted in accordance with the "Preferred Reporting Items for Systematic Reviews and Meta-Analysis" guidelines (PRISMA-P). To define the research question, the PICOS (Patient-InterventionComparison-Outcome) strategy was used, as shown in Supplementary Material Table 1 (available from https:// drive.google.com/file/d/106nzdLxTUbI7rRQt9s0kAsA_ V8rOvxe6/view? usp=sharing). The analytic methods and inclusion criteria for the present review were documented in a systematic review protocol recorded on the PROSPERO platform of the University of York, United Kingdom (CRD42020145349).

\section{Information sources}

A search was conducted in the PubMed (via Medline), LILACS, IBECS, CUMED, BINACIS, EMBASE, Cochrane Library and Web of Science databases and in the grey literature to find studies in which the aim had been to investigate associations between polyphenol administration and rheumatic diseases. This search was conducted between July 22, 2019, and September 10, 2020.

The descriptors used were previously defined in the $\mathrm{MeSH}$, DECS and Emtree databases. These related to "Rheumatic Diseases" or "Disease, Rheumatic" or "Rheumatic Disease" or "Rheumatism" and "Polyphenols" or "Provinols". Detailed search strategies are presented in Supplementary Material that is available from https:// drive.google.com/file/d/106nzdLxTUbI7rRQt9s0kAsA_V8rOvxe6/ view? usp=sharing.

\section{Inclusion and exclusion criteria}

Only double-blind randomized controlled trials (RCTs) analyzing outcomes from interventions consisting of polyphenol administration to improve disease activity were included in this study. No restrictions on the date of publication or language used were imposed in relation to article selection.

The exclusion criteria encompassed duplicates, in vitro studies, reviews, cross-sectional or observational studies, case reports, case series, ecological studies, studies about other morbidities or studies on pregnant women, children or teenagers.

\section{Data collection process}

The references retrieved through the search strategies were exported to an Endnote file (Clarivate Analytics, Philadelphia, United States), and duplicates were removed. Two independent researchers (HNC and APD) selected titles and abstracts; potential texts were evaluated to check their eligibility based on the criteria described above. A third researcher (NSG) resolved any discrepancies resulting from disagreements between HNC and APD. In addition, the grey literature, such as monographs, dissertations, theses and conference proceedings, was assessed based on references in the articles selected. 


\section{Data extraction}

Two independent researchers (HNC and APD) extracted data on features such as study design, name of the first author, publication year, participants, participants' age and sex, intervention features, placebo groups (sample, age, sex), intervention types (polyphenol use), sample size and outcomes (rheumatic disease activity: pain, functional capacity, inflammatory markers, laboratory markers, antioxidant activity and quality of life).

\section{Evaluation of the methodological quality of the studies included}

The quality of the RCT methodology was assessed through the Cochrane tool for risk of bias in Cochrane randomized studies (RoB 2.0, London, England), which classifies studies as having high or low risk of bias. The methodological quality was assessed by two independent researchers (HNC and APD), and a third researcher (NSG) resolved any score divergences.

\section{RESULTS}

The search in the databases and in the grey literature resulted in 646 studies. In total, 641 publications were evaluated after duplicate removal $(n=5)$. From among these, 542 articles were excluded from the sample because of the title and 66 through reading the abstract. The remaining 33 studies were then read in full (Figure 1). Sixteen articles were excluded during this text analysis stage due to their methodologies (pilot studies or experimental studies). Thus, 17 articles composed the final sample of the present review (Figure 1).

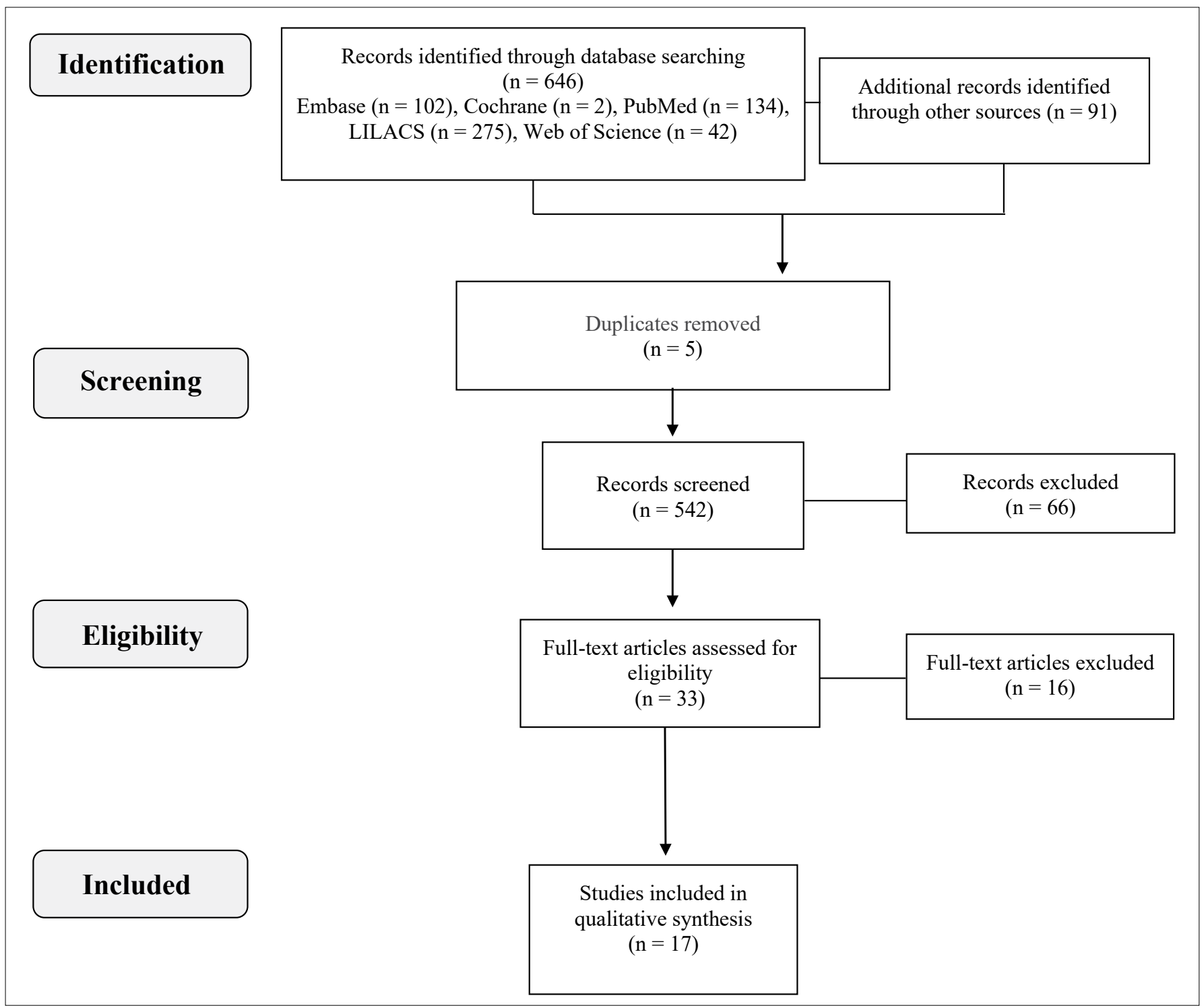

Figure 1. PRISMA flow of studies included in the review. 
Among these 17 clinical trials, 52.94\% $(\mathrm{n}=9)$ were published in the last five years (2015-2019); 23.53\% were conducted in the United States $(n=4), 17.65 \%$ in Iran $(n=3), 11.65 \%$ in India $(\mathrm{n}=2), 5.89 \%$ in $\operatorname{Iraq}(\mathrm{n}=1), 5.89 \%$ in Armenia $(\mathrm{n}=1), 5.89 \%$ in Australia $(n=1), 5.89 \%$ in Japan $(n=1), 5.89 \%$ in Egypt $(n=1)$, $5.89 \%$ in Belgium $(n=1), 5.89 \%$ in Brazil $(n=1)$ and $5.89 \%$ in Finland $(n=1)$. The number of individuals evaluated reached 1,244 (the minimum and maximum sample groups encompassed 17 and 201 subjects, respectively). Studies reporting the sample characteristics $(\mathrm{n}=14)$ showed that $55.55 \%$ of the participants were women $(n=691)$. In all the studies, the total of 1,244 participants were in the age group 45-85 years.

The analysis on the studies included in this review was demonstrated through three tables that were organized according to the pathological conditions found. Table 1 presents the results found for studies that assessed OA; Table 2, RA; and Table 3, the studies that assessed both of these diseases plus fibromyalgia (rheumatoid arthritis and fibromyalgia; osteoarthritis and rheumatoid arthritis).

Among RDs, $64.71 \%$ of the studies assessed osteoarthritis $(\mathrm{n}=11)$ (Table 1); 23.53\%, rheumatoid arthritis $(\mathrm{n}=4)$ (Table 2$)$; $5.88 \%$, rheumatoid arthritis and fibromyalgia; and 5.88\%, osteoarthritis and rheumatoid (Table 3).

Polyphenols were administered in the form of either capsules of a specific polyphenol or concentrates of food sources of polyphenols (Online Supplementary Material, available from: https://drive.google.com/file/d/106nzdLxTUbI7rRQt9s0kAsA_ V8rOvxe6/view? usp=sharing). The polyphenol doses administered ranged from $42 \mathrm{mg} /$ day $^{17}$ to $1,585 \mathrm{mg} /$ day. ${ }^{18}$ Table 2 in Online Supplementary Material (available from https://drive.google. com/file/d/106nzdLxTUbI7rRQt9s0kAsA_V8rOvxe6/view?us$\mathrm{p}=$ sharing) describes the doses administered, their source and the polyphenol composition.

The intervention with polyphenols to mitigate/rule out disease activity (pain, functional capacity, inflammatory markers, laboratory markers, antioxidant activity and quality of life) of rheumatic diseases (outcome variable) led to positive results in $94.12 \%$ of the studies selected. Pain improved in $64.70 \%$ of the cases $(n=11)$, based on assessment using a visual analogue scale, and inflammation improved in $58.82 \%$ of the cases $(n=10)$. The only study that recorded negative results for RD mitigation only assessed participants' antioxidant capacity based on biochemical markers. ${ }^{19}$

The lack of information about the methodological characteristics of the studies evaluated in the present review made it difficult to classify the quality of evidence, as shown in Figure 2. Eight studies did not mention any method of randomization. ${ }^{19-26}$ Among all the articles, five did not mention the allocation method. . $18,22,23,27^{2}$ Nine studies had a high risk of bias because the study participants were not blinded to either the intervention or the placebo groups. ${ }^{20,21,24,25,29,30}$ In six studies, an imbalance in either the number of or the reasons for missing data, between the experimental and control groups, was observed. ${ }^{18,20,25,26,28,30}$ Lastly, just four authors described all the outcomes targeted and measured. ${ }^{20,26,28,30}$

\section{DISCUSSION}

We found out that polyphenols are capable of helping to treat RDs, with reductions of inflammation and pain. Therefore, their use in treatments for RDs can impact the quality of life of the individuals affected.

To the best of our knowledge, the present systematic review was a pioneer in assessing the association between polyphenol administration and mitigation/improvement of rheumatic disease activity in humans.

Positive effects from polyphenol intake on the improvement/ mitigation of rheumatic disease activity were observed in most of the studies selected (94.12\% of the articles)..$^{17,18,20-33}$ Based on the information in these articles, pain and inflammation in patients with osteoarthritis or rheumatoid arthritis were the main symptoms mitigated/relieved in the populations assessed. . $^{17,18,20,21,22,28,32}$

The studies showed positive results in terms of reduction of $\mathrm{RD}$ activity, due to pain relief; ; $^{18,20,21,22,28,30,31,32}$ reductions of the levels of cytokines and pro-inflammatory markers such as $\mathrm{C}$-reactive protein (CRP), erythrocyte sedimentation rate (ESR), interleukins 6 (IL6 ) and $1 \beta$ (IL- $1 \beta$ ) and tumor necrosis factor $\alpha$ (TNF- $\alpha){ }^{18,23,27,29,30}$ reductions of disease activity as assessed through reductions of the levels of undercarboxylated osteocalcin (ucOc), matrix metalloproteinases (MMP-3), anti-cyclic citrullinated peptide (anti-CCP) and Coll2-1 markers; ${ }^{17,18,23,26}$ increased levels of anti-inflammatory cytokines, such as IL-13; ${ }^{28}$ and improvements in oxidative stress caused by increasing the levels of antioxidant enzymes such as superoxide dismutase (SOD) and reducing malondialdehyde (MDA). ${ }^{33}$

RD improvement was mostly identified by means of biochemical markers that indicate normal or pathological functioning. ${ }^{34}$ Inflammatory biomarker levels are increased in $\mathrm{RDs}$, and are associated with the pain and other symptoms of the disease. ${ }^{6}$ They can be divided into the following categories: pro-inflammatory cytokines, anti-inflammatory cytokines, adipokines and chemokines. Pro-inflammatory cytokines are mainly produced by adipocytes: the main ones are IL-6, IL-8, IL- $1 \beta$ and TNF- $\alpha .{ }^{34}$ Specific biomarkers of RD, such as MMP, stand out among them. These biomarkers belong to a family of enzymes that account for the extracellular degradation of cartilage matrix components, including collagen type II and aggrecan; they change bone metabolism, cartilage and the synovial membrane, which leads to joint destruction. ${ }^{35}$

There is a specific treatment for each clinical condition in RDs. These treatments can range from medication to secondary therapies such as individualized diet therapy. ${ }^{6,36}$ Overall, drug therapy involves use of non-steroidal anti-inflammatory drugs (NSAIDs) such as diclofenac and meloxicam, but these substances lead to 
Table 1. Features of randomized controlled trials evaluating the effect of polyphenol administration on osteoarthritis

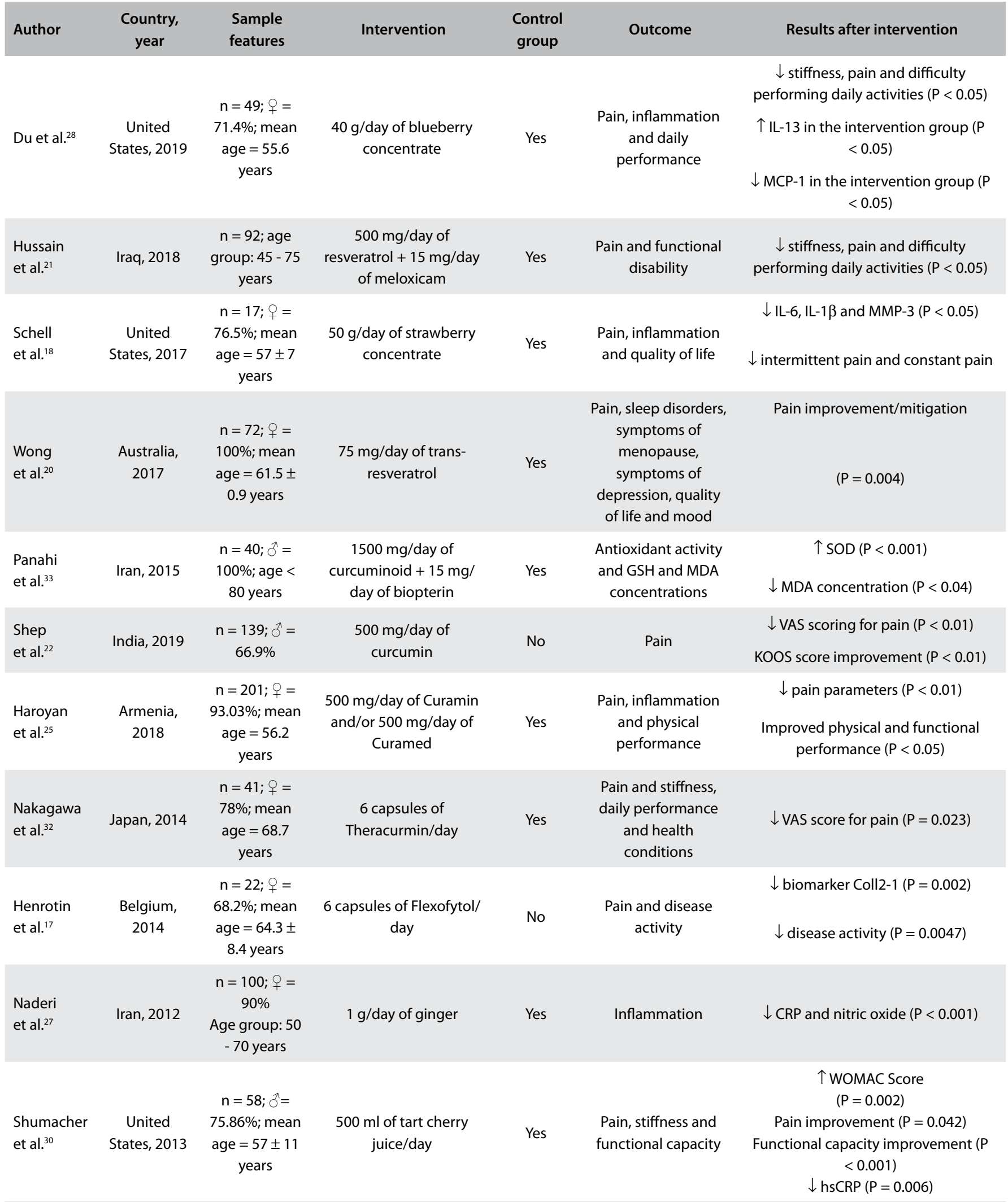

VAS = visual analogue scale; $\mathrm{KOOS}=$ Knee Injury and Osteoarthritis Outcome Score; MDA = malondialdehyde; IL = interleukin; MCP-1 = monocyte chemoattractant protein-1; CRP = C-reactive protein; MMP-3 = matrix metalloproteinase-3; M1 $=\delta$-(3,4-dihydroxy-phenyl) $-\boldsymbol{\gamma}$-valerolactone; SOD $=$ superoxide dismutase; Coll2-1 = cartilage biomarker; WOMAC = Western Ontario and McMaster Universities Osteoarthritis Index; hsCRP = high-sensitivity C-reactive protein. 
Table 2. Features of randomized controlled trials evaluating the effect of polyphenol administration on rheumatoid arthritis

\begin{tabular}{|c|c|c|c|c|c|c|}
\hline Author & Country, year & Sample features & Intervention & Control group & Outcome & Results after intervention \\
\hline $\begin{array}{l}\text { Khojah } \\
\text { et al. }{ }^{23}\end{array}$ & Egypt, 2018 & $\mathrm{n}=100 ;$; $=68 \%$ & $\begin{array}{l}1 \mathrm{~g} / \text { day of resveratrol + } \\
\text { antirheumatic drugs }\end{array}$ & Yes & $\begin{array}{l}\text { Biochemical and } \\
\text { inflammatory } \\
\text { markers }\end{array}$ & $\begin{array}{c}\downarrow \text { CRP }(\mathrm{P}<0.05) \\
\downarrow \text { ESR, ucOC, MMP-3, } \\
\text { TNF- } \alpha \text { and IL-6 }(\mathrm{P}<0.001)\end{array}$ \\
\hline $\begin{array}{l}\text { Chandran } \\
\text { and } \\
\text { Goel }^{24}\end{array}$ & India, 2012 & $\begin{array}{c}\mathrm{n}=45 ; q=84.4 \% ; \\
\text { mean age }=47.8 \text { years }\end{array}$ & $\begin{array}{c}500 \mathrm{mg} / \text { day of curcumin } \\
+50 \mathrm{mg} / \text { day of sodium } \\
\text { diclofenac }\end{array}$ & Yes & Disease activity & $\begin{array}{c}\text { Mitigating disease activity } \\
\qquad(\mathrm{P}<0.05) \\
\downarrow \mathrm{CRP}(\mathrm{P}<0.05)\end{array}$ \\
\hline $\begin{array}{l}\text { Thimotéo } \\
\text { et al. }{ }^{26}\end{array}$ & Brazil, 2018 & $\begin{array}{c}\mathrm{n}=41 ; q=100 \% \\
\text { mean age }=52.75 \\
\text { years }\end{array}$ & $\begin{array}{c}500 \mathrm{ml} \text { of reduced- } \\
\text { energy cranberry juice/ } \\
\text { day }\end{array}$ & Yes & $\begin{array}{l}\text { Biochemical } \\
\text { markers and } \\
\text { disease activity }\end{array}$ & $\begin{array}{l}\text { Mitigating disease activity } \\
\qquad(\mathrm{P}=0.048) \\
\downarrow \text { anti-CCP }(\mathrm{P}=0.034)\end{array}$ \\
\hline
\end{tabular}

$\mathrm{ESR}=$ erythrocyte sedimentation rate; $\mathrm{UCOC}=$ undercarboxylated osteocalcin; $\mathrm{CRP}=\mathrm{C}$-reactive protein; $\mathrm{MMP}-3=$ matrix metalloproteinase-3; $\mathrm{IL}=$ interleukin;

TNF = tumor necrosis factor; Anti-CCP = anti-cyclic citrullinated peptide.

Table 3. Features of randomized controlled trials evaluating the effect of polyphenol administration on rheumatic diseases

\begin{tabular}{|c|c|c|c|c|c|c|c|}
\hline Author & Country, year & $\begin{array}{l}\text { Sample } \\
\text { features }\end{array}$ & Intervention & $\begin{array}{l}\text { Control } \\
\text { group }\end{array}$ & Rheumatic disease & Outcome & $\begin{array}{l}\text { Results after } \\
\text { intervention }\end{array}$ \\
\hline & & & & & & & $\begin{array}{l}\downarrow \text { rheumatoid } \\
\text { arthritis activity } \\
\quad(P=0.03)\end{array}$ \\
\hline $\begin{array}{l}\text { Hänninen, } \\
\text { et al. }{ }^{31}\end{array}$ & Finland, 2000 & 115 & Diet of living food ${ }^{*}$ & Yes & $\begin{array}{l}\text { Rheumatoid arthritis } \\
\text { and fibromyalgia }\end{array}$ & $\begin{array}{l}\text { Symptoms of } \\
\text { rheumatoid arthritis } \\
\text { and fibromyalgia }\end{array}$ & $\begin{array}{l}\text { Joint stiffness } \\
\text { mitigation } \\
(P=0.001)\end{array}$ \\
\hline
\end{tabular}

Pain mitigation

$(P=0.003)$

\begin{tabular}{|c|c|c|c|c|c|c|c|}
\hline $\begin{array}{l}\text { Bitler, } \\
\text { et al. }{ }^{29}\end{array}$ & $\begin{array}{l}\text { United States, } \\
2007\end{array}$ & 90 & $\begin{array}{c}400 \mathrm{mg} / \text { day of } \\
\text { olive pulp }\end{array}$ & Yes & $\begin{array}{l}\text { Osteoarthritis and } \\
\text { rheumatoid arthritis }\end{array}$ & $\begin{array}{l}\text { Ability to perform } \\
\text { daily activities, } \\
\text { disease activity and } \\
\text { inflammation }\end{array}$ & $\downarrow \mathrm{CRP}(\mathrm{P}<0.01)$ \\
\hline
\end{tabular}

"Diet of living food consisted of vegan diet without cooking; CRP = C-reactive protein.

several side effects like peptic ulcers. Accordingly, anti-inflammatory compounds can come from food. Thus, it is essential to define the compounds capable of mitigating pain and inflammation.

Polyphenols have been described in the literature as potent anti-inflammatory drugs that can be used to minimize the effects of diseases on different health conditions. ${ }^{36}$ Polyphenols link to aromatic rings that reduce free radicals, inhibit formation of reactive species during metabolism, perform anti-inflammatory immunomodulatory actions ${ }^{3}$ and have an anabolic effect on cartilage cells. ${ }^{37}$ Experimental studies have already shown the beneficial action of flavonoids with regard to increasing cartilage anabolic activity and improving the levels of insulin-like growth factor-1 (IGF-1), osteocalcin and physical morphogenetic protein. ${ }^{38}$ Reproduced clinical trials have shown that blueberries are a source of polyphenols that have anti-inflammatory effects and can improve gait capacity parameters among older adults. ${ }^{39,40}$

The magnitude of the results recorded can change depending on polyphenol type, dose (extract, fruit concentrate or others), delivery route (oral or injection into the synovial fluid), association with other compounds (such as drug therapy) and the types of markers analyzed. ${ }^{17}$

Polyphenols from different sources were administered in the studies reviewed here. This made it difficult to interpret the results, 


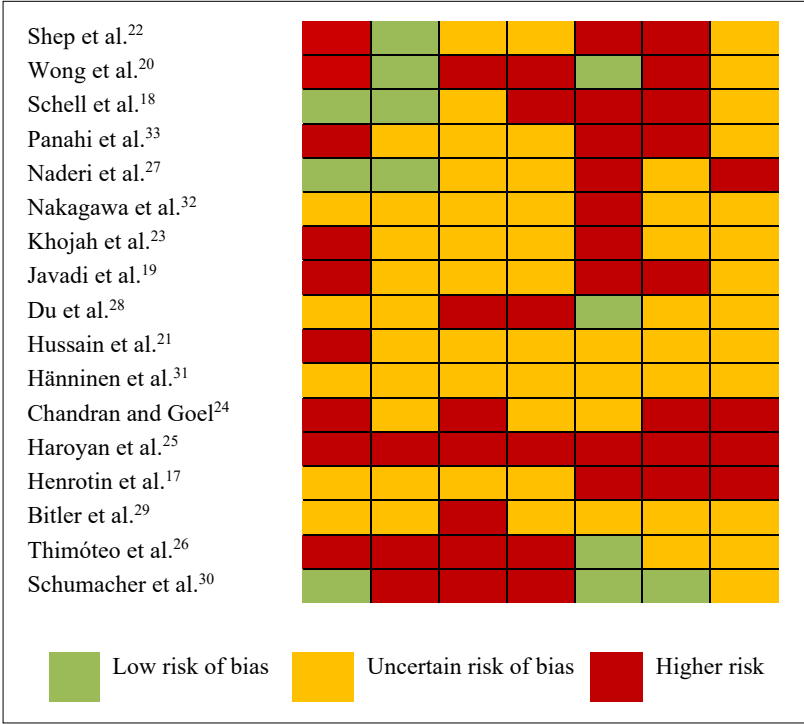

Figure 2. Assessment of the quality of randomized clinical trials selected to form part of the present review, 2020.

since there may have different mechanisms of action ${ }^{41}$ and even different degrees of bioavailability. ${ }^{42-45}$ However, studies that have reviewed the effects of polyphenols for prevention or treatment of several diseases used a wide variety of sources and different quantities of polyphenols, ${ }^{46-48}$ given the heterogeneity of sources of polyphenols and the scarcity of existing literature on this subject from primary studies. Lack of information about the medications or dietary supplements used by participants in the 17 studies evaluated may have been another form of bias. Some studies did not mention the type or dosage of medication administered to control the diseases assessed. Therefore, doubts regarding the effects of polyphenols in isolation are raised.

Lack of clarity about several aspects of the studies evaluated in the present review made it difficult to classify the quality of evidence found in these studies. According to Gordis et al., ${ }^{49}$ randomized controlled clinical trials presenting good methodological quality are characterized by clear planning, execution and reporting, and should guarantee adequate confidentiality of allocation, degree of blinding and randomization. Thus, when these studies are meticulously designed, executed and reported, they can be considered to represent the gold standard for assessing the effectiveness of healthcare interventions. However, despite the large numbers of studies included in the search and analysis processes of the present review, it was not possible to perform a meta-analysis. This was because the studies selected assessed different evaluation parameters for disease activity in RDs, and also used different doses and types of polyphenols.

Given the lack of consensus on the best doses and types of polyphenols in the studies assessed in this review, the results should be interpreted with caution and attention. There is a need to conduct primary studies that focus on the minimum dose necessary to achieve the protective effects of polyphenols on the health of patients with RDs. Accordingly, for better guidance for healthcare professionals and patients, future research must focus on, and align with, daily recommendations for foods that are known to be source of polyphenols that are capable of preventing and protecting health and helping in treating RDs, due to the importance of consuming such bioactive compounds.

Despite the bias in the primary data sources that is reported here, this review produced promising results, considering that, overall, the dietary intake from polyphenol-rich sources had positive effects with regard to reducing both inflammation and the symptoms of RDs.

\section{REFERENCES}

1. Woolf AD. Global burden of osteoarthritis and musculoskeletal diseases. BMC Musculoskelet Disord. 2015;16(Suppl 1):S3. PMC4674868; https:// doi.org/10.1186/1471-2474-16-S1-S3.

2. Ferreira PL, Gonçalves SP, Ferreira LN, et al. Assessing quality of life of self-reported rheumatic patients. Rheumatol Int. 2016;36(9):1265-74. PMID: 27378230; https://doi.org/10.1007/s00296-016-3517-0.

3. Oliviero F, Scanu A, Zamudio-Cuevas Y, Punzi L, Spinella P. Antiinflammatory effects of polyphenols in arthritis. J Sci Food Agric. 2018;98(5):1653-9. PMID: 28886220; https://doi.org/10.1002/jsfa.8664.

4. González CM, Carmona L, de Toro J, et al. Perceptions of patients with rheumatic diseases on the impact on daily life and satisfaction with their medications: RHEU-LIFE, a survey to patients treated with subcutaneous biological products. Patient Prefer Adherence. 2017;11:1243-52. Erratum in: Patient Prefer Adherence. 2019;13:665. PMID: 28790806; https://doi. org/10.2147/ppa.s137052

5. Abrão AL, Santana CM, Bezerra AC, et al. What rheumatologists should know about orofacial manifestations of autoimmune rheumatic diseases. Rev Bras Reumatol. 2016:S0482-5004(16)00021-8. PMID 26947177; https://doi.org/10.1016/j.rbre.2016.02.006.

6. Silman AJ, Pearson JE. Epidemiology and genetics of rheumatoid arthritis. Arthritis Res. 2002;4 Suppl 3(Suppl 3):S265-72. PMID: 12110146 ; https://doi.org/10.1186/ar578

7. Vina ER, Kwoh CK. Epidemiology of osteoarthritis: literature update. Curr Opin Rheumatol. 2018;30(2):160-7. PMID:29227353; https://doi:10.1097/ BOR.0000000000000479.

8. Aletaha D, Smolen JS. Diagnosis and Management of Rheumatoid Arthritis: A Review. JAMA. 2018;320(13):1360-72. PMID: 30285183; https://doi.org/10.1001/jama.2018.13103.

9. Winkvist A, Bärebring L, Gjertsson I, Ellegård L, Lindqvist HM. A randomized controlled cross-over trial investigating the effect of antiinflammatory diet on disease activity and quality of life in rheumatoid arthritis: the Anti-inflammatory Diet In Rheumatoid Arthritis (ADIRA) study protocol. Nutr J. 2018;17(1):44. PMID: 29678183; https://doi. org/10.1186/s12937-018-0354-х. 
10. Hu Y, Sparks JA, Malspeis S, Costenbader KH, et al. Long-term dietary quality and risk of developing rheumatoid arthritis in women. Ann Rheum Dis. 2017;76(8):1357-64. PMID: 28137914; https://doi. org/10.1136/annrheumdis-2016-210431.

11. Islam MA, Alam F, Solayman M, et al. Dietary Phytochemicals: Natural Swords Combating Inflammation and Oxidation-Mediated Degenerative Diseases. Oxid Med Cell Longev. 2016;2016:5137431. PMID: 27721914; https://doi.og/10.1155/2016/5137431.

12. Velderrain-Rodríguez GR, Palafox-Carlos H, Wall-Medrano A, et al. Phenolic compounds: their journey after intake. Food Funct. 2014;5(2):189-97. PMID: 24336740; https://doi.org/10.1039/c3fo60361j.

13. Ahmed S, Rahman A, Hasnain A, et al. Green tea polyphenol epigallocatechin-3-gallate inhibits the IL-1 beta-induced activity and expression of cyclooxygenase- 2 and nitric oxide synthase- 2 in human chondrocytes. Free Radic Biol Med. 2002;33(8):1097-105. PMID: 12374621; https://doi.org/10.1016/S0891-5849(02)01004-3.

14. Zhang Z, Leong DJ, Xu L, et al. Curcumin slows osteoarthritis progression and relieves osteoarthritis-associated pain symptoms in a post-traumatic osteoarthritis mouse model. Arthritis Res Ther. 2016;18(1):128. PMID: 27260322; https://doi.org/10.1186/s13075-016-1025-y.

15. Park C, Moon DO, Choi IW, et al. Curcumin induces apoptosis and inhibits prostaglandin $\mathrm{E}(2)$ production in synovial fibroblasts of patients with rheumatoid arthritis. Int J Mol Med. 2007;20(3):365-72. PMID: 17671742; https://doi.org/10.3892/ijmm.20.3.365.

16. Del Bo' C, Bernardi S, Marino M, et al. Systematic Review on Polyphenol Intake and Health Outcomes: Is there Sufficient Evidence to Define a Health-Promoting Polyphenol-Rich Dietary Pattern? Nutrients. 2019;11(6):1355. PMID: 31208133; https://doi.org/10.3390/nu11061355.

17. Henrotin Y, Gharbi M, Dierckxsens Y, et al. Decrease of a specific biomarker of collagen degradation in osteoarthritis, Coll2-1, by treatment with highly bioavailable curcumin during an exploratory clinical trial. BMC Complement Altern Med. 2014;14:159. PMID: 24886572; https://doi. org/10.1186/1472-6882-14-159.

18. Schell J, Scofield RH, Barrett JR, et al. Strawberries Improve Pain and Inflammation in Obese Adults with Radiographic Evidence of Knee Osteoarthritis. Nutrients. 2017;9(9):949. PMID: 28846633; https://doi. org/10.3390/nu9090949.

19. Javadi F, Eghtesadi S, Ahmadzadeh A, et al. The effect of quercetin on plasma oxidative status, C-reactive protein and blood pressure in women with rheumatoid arthritis. Int J Prev Med. 2014;5(3):293-301. PMID: 24829713.

20. Wong RHX, Evans HM, Howe PRC. Resveratrol supplementation reduces pain experience by postmenopausal women. Menopause. 2017;24(8):91622. PMID: 28350759; https://doi.org/10.1097/GME.0000000000000861.

21. Hussain SA, Marouf BH, Ali ZS, Ahmmad RS. Efficacy and safety of co-administration of resveratrol with meloxicam in patients with knee osteoarthritis: a pilot interventional study. Clin Interv Aging. 2018;13:1621-30. PMID: 30233159; https://doi.org/10.2147/CIA.S172758.

22. Shep D, Khanwelkar C, Gade P, Karad S. Safety and efficacy of curcumin versus diclofenac in knee osteoarthritis: a randomized open-label parallel-arm study. Trials. 2019;20(1):214. PMID: 30975196; https://doi. org/10.1186/s13063-019-3327-2.

23. Khojah HM, Ahmed S, Abdel-Rahman MS, Elhakeim EH. Resveratrol as an effective adjuvant therapy in the management of rheumatoid arthritis: a clinical study. Clin Rheumatol. 2018;37(8):2035-42. PMID: 29611086; https://doi.org/10.1007/s10067-018-4080-8.

24. Chandran B, Goel A. A randomized, pilot study to assess the efficacy and safety of curcumin in patients with active rheumatoid arthritis. Phytother Res. 2012;26(11):1719-25. PMID:22407780; https://doi.org/10.1002/ptr.4639.

25. Haroyan A, Mukuchyan V, Mkrtchyan N, et al. Efficacy and safety of curcumin and its combination with boswellic acid in osteoarthritis: a comparative, randomized, double-blind, placebo-controlled study. BMC Complement Altern Med. 2018;18(1):7. PMID: 29316908; https:// doi.org/10.1186/s12906-017-2062-z.

26. Thimóteo NSB, Iryioda TMV, Alfieri DF, et al. Cranberry juice decreases disease activity in women with rheumatoid arthritis. Nutrition. 2019;60:112-7.PMID:30553231; https://doi.org/10.1016/j.nut.2018.10.010.

27. Naderi Z, Mozaffari-Khosravi H, Dehghan A, Nadjarzadeh A, Huseini HF.Effect of ginger powder supplementation on nitric oxide and $C$-reactive protein in elderly knee osteoarthritis patients: A 12-week double-blind randomized placebo-controlled clinical trial. J Jradit Complement Med. 2015;6(3):199203. PMID: 27419081; https://doi.org/10.1016/j.jtcme.2014.12.007.

28. Du C, Smith A, Avalos M, et al. Blueberries Improve Pain, Gait Performance, and Inflammation in Individuals with Symptomatic Knee Osteoarthritis. Nutrients. 2019;11(2):290. PMID: 30699971; https://doi.org/10.3390/nu1 1020290

29. Bitler CM, Matt K, Irving M, et al. Olive extract supplement decreases pain and improves daily activities in adults with osteoarthritis and decreases plasma homocysteine in those with rheumatoid arthritis. Nutri. Res 2017;27(8):470-7. https://doi.org/10.1016/j.nutres.2007.06.003.

30. Schumacher HR, Pullman-Mooar S, Gupta SR, et al. Randomized doubleblind crossover study of the efficacy of a tart cherry juice blend in treatment of osteoarthritis (OA) of the knee. Osteoarthritis Cartilage. 2013;21(8):103541. PMID: 23727631; https://doi.org/10.1016/j.joca.2013.05.009.

31. Hänninen, Kaartinen K, Rauma AL, et al. Antioxidants in vegan diet and rheumatic disorders. Toxicology. 2000;155(1-3):45-53. PMID: 11156742; https://doi.org/10.1016/S0300-483X(00)00276-6

32. Nakagawa Y, Mukai S, Yamada S, et al. Short-term effects of highly-bioavailable curcumin for treating knee osteoarthritis: a randomized, double-blind, placebo-controlled prospective study. J Orthop Sci. 2014;19(6):933-9.PMID: 25308211; https://doi.org/10.1007/s00776-014-0633-0.

33. Panahi Y, Alishiri GH, Parvin S, Sahebkar A. Mitigation of Systemic Oxidative Stress by Curcuminoids in Osteoarthritis: Results of a Randomized Controlled Trial. J Diet Suppl. 2016;13(2):209-20. PMID: 25688638; https://doi.org/10.3109/19390211.2015.1008611.

34. Volp AC, Alfenas R de C, Costa NM, et al. Capacidade dos biomarcadores inflamatórios em predizer a síndrome metabólica [Inflammation biomarkers capacity in predicting the metabolic syndrome]. Arq Bras Endocrinol Metabol. 2008;52(3):537-49. PMID: 18506280; https://doi. org/10.1590/S0004-27302008000300015. 
35. Garnero P, Sornay-Rendu E, Claustrat B, Delmas PD. Biochemical markers of bone turnover, endogenous hormones and the risk of fractures in postmenopausal women: the OFELY study.J Bone Miner Res.2000;15(8):152636. PMID: 10934651; https://doi.org/10.1359/jbmr.2000.15.8.1526.

36. Rodrigues AP, Rodrigues WP, Nogueira TBSN, Souza WJ, Souza MNA. Qualidade de vida em pacientes portadores de doenças reumáticas. Revista Brasileira de Educação e Saúde. 2012;9(1):6-13. https://doi. org/10.18378/rebes.v9i1.6331.

37. Horcajada MN, Offord E. Naturally plant-derived compounds: role in bone anabolism. Curr Mol Pharmacol. 2012;5(2):205-18. PMID: 21787284; https://doi.org/10.2174/1874467211205020205.

38. Williamson G, Holst B. Dietary reference intake (DRI) value for dietary polyphenols: are we heading in the right direction? Br J Nutr. 2008;99 Suppl 3:S55-8. PMID: 18598589; https://doi.org/10.1017/S0007114508006867.

39. Schrager MA, Hilton J, Gould R, KellyVE. Effects of blueberry supplementation on measures of functional mobility in older adults. Appl Physiol Nutr Metab. 2015;40(6):543-9. PMID:25909473; https:/doi.org/10.1139/apnm-2014-0247.

40. McLeay Y, Barnes MJ, Mundel T, et al. Effect of New Zealand blueberry consumption on recovery from eccentric exercise-induced muscle damage. J Int Soc Sports Nutr. 2012;9(1):19. PMID: 22564864; https:// doi.org/10.1186/1550-2783-9-19.

41. Vitale M, Masulli M, Rivellese AA, et al. Dietary intake and major food sources of polyphenols in people with type 2 diabetes: The TOSCA. IT Study. Eur J Nutr. 2018;57(2):679-88. PMID: 28004268; https://doi. org/10.1007/s00394-016-1355-1.

42. Jacobson EA, Newmark H, Baptista J, Bruce WR. A preliminary investigation of the metabolism of dietary phenolics in humans. Nutrition-Reports-International. 1983;28(6):1409-17.

43. Hollman PC, van Trijp JM, Buysman MN, et al. Relative bioavailability of the antioxidant flavonoid quercetin from various foods in man. FEBS Lett. 1997;418(1-2):152-6. PMID: 9414116; https://doi.org/10.1016/ S0014-5793(97)01367-7.

44. Lapidot T, Harel S, Granit R, Kanner J. Bioavailability of red wine anthocyanins as detected in human urine. J Agri Food Chem. 1998;46(10):4297-302. https://doi.org/10.1021/jf980007o.

45. Scalbert A, Williamson G. Dietary intake and bioavailability of polyphenols. J Nutr. 2000;130(8S Suppl):2073S-85S. PMID: 10917926; https://doi.org/10.1093/jn/130.8.2073S.

46. Somerville V, Bringans C, Braakhuis A. Polyphenols and Performance: A Systematic Review and Meta-Analysis. Sports Med. 2017;47(8):1589-99. PMID: 28097488; https://doi.org/10.1007/s40279-017-0675-5.

47. Coe S, Ryan L. Impact of polyphenol-rich sources on acute postprandial glycaemia: a systematic review. J Nutr Sci. 2016;5:e24. PMID: 27547387; https://doi.org/10.1017/jns.2016.11.

48. Lamport DJ, Dye L, Wightman JD, Lawton CL. The effects of flavonoid and other polyphenol consumption on cognitive performance: a systematic research review of human experimental and epidemiological studies. Nutritional and Aging. 2012;1(1):5-25. https://doi.org/10.3233/ NUA-2012-0002.

49. Gordis L. Epidemiology. Philadelphia: Saunders Co.; 1996.

Authors' contributions: Coletro HN: formal analysis (equal), methodology (equal), writing-original draft (equal) and writing-review and editing (equal); Diniz AP: formal analysis (equal), methodology (equal), writing-original draft (equal) and writing-review and editing (equal); Guimarães NS: methodology (equal), writing-original draft (equal) and writing-review and editing (equal); Carraro JCC: conceptualization (lead), methodology (lead), supervision (lead) and writing-review and editing (lead); Mendonça RD: conceptualization (lead), methodology (lead), supervision (lead) and writing-review and editing (lead); and Meireles AL: conceptualization (lead), methodology (equal), project administration (lead), supervision (lead) and writing-review and editing (equal)

Sources of finding: This project was funded by Universidade Federal de Ouro Preto (UFOP) and Coordenação de Aperfeiçoamento de Pessoal de Nível Superior, Brazil (CAPES), under finance code 001. HNC is a Doctoral Student at Universidade Federal de Ouro Preto (UFOP); grant through finance code 001 from Coordenação de Aperfeiçoamento de Pessoal de Nível Superior, Brazil (CAPES). APD is a Doctoral Student at Universidade Federal de Ouro Preto (UFOP); grant through finance code 001 from Coordenação de Aperfeiçoamento de Pessoal de Nível Superior, Brazil (CAPES).

NSG is a former Postdoctoral Fellow at Universidade Federal de Ouro Preto (UFOP); grant through finance code 001 from Coordenação de Aperfeiçoamento de Pessoal de Nível Superior, Brazil (CAPES). The funders had no role in the study design, data collection and analysis, decision to publish or preparation of the article

Conflict of interest: The authors declare that they did not have any conflict of interest; they were fully responsible for the content and writing of the manuscript

Date of first submission: December 18, 2020

Last received: March 26, 2021

Accepted: April 22, 2021

\author{
Address for correspondence: \\ Adriana Lúcia Meireles \\ Universidade Federal de Ouro Preto (UFOP) \\ Campus Morro do Cruzeiro, s/no \\ Bauxita - Ouro Preto (MG) - Brasil \\ CEP 35400-000 \\ Tel. (+55 31) 3559-1838 \\ E-mail: adriana.meireles@ufop.edu.br
}

